\title{
Public recognition of mental disorders and beliefs about treatment: changes in Australia over 16 years
}

\author{
Nicola J. Reavley and Anthony F. Jorm
}

\section{Background}

A 1995 Australian national survey of mental health literacy showed poor recognition of disorders and beliefs about treatment that differed from those of health professionals. A similar survey carried out in 2003/4 showed some improvements over 8 years.

\section{Aims}

To investigate whether recognition of mental disorders and beliefs about treatment have changed over a 16-year period.

\section{Method}

A national survey of 6019 adults was carried out in 2011 using the same questions as the 1995 and 2003/4 surveys.

\section{Results}

Results showed improved recognition of depression and more positive ratings for a range of interventions, including help from mental health professionals and antidepressants.

\section{Conclusions}

Although beliefs about effective medications and interventions have moved closer to those of health professionals since the previous surveys, there is still potential for mental health literacy gains in the areas of recognition and treatment beliefs for mental disorders. This is particularly the case for schizophrenia.

\section{Declaration of interest}

None.
Mental health literacy, which has been defined as 'knowledge and beliefs about mental disorders which aid their recognition, management or prevention' ${ }^{1}$ is one of the factors that has an impact on whether a person receives appropriate help for mental health problems. In 1995, a national survey of mental health literacy was carried out in 2164 Australian adults. ${ }^{1}$ Participants were randomly assigned to receive either a depression or schizophrenia vignette and were then asked a series of questions covering recognition of the disorder and beliefs about the likely helpfulness or harmfulness of a range of interventions. Although most respondents were able to identify some kind of mental health problem, only $39 \%$ of respondents correctly identified depression and $27 \%$ correctly identified schizophrenia. Comparison of the survey results with those from a survey of health professionals using the same questions revealed considerable differences between public and professional beliefs, particularly those relating to standard psychiatric treatments. ${ }^{2,3}$ Concern about the relatively low levels of mental health literacy found in such studies led to campaigns to improve this in a number of countries. ${ }^{4-7}$ In an effort to explore the effects of such campaigns in Australia, a second national mental health literacy survey was conducted in 2003/4. ${ }^{8}$ Involving 3998 adults, this survey included two additional vignettes: depression with suicidal thoughts and chronic schizophrenia. It incorporated questions from the 1995 survey as well as some additional items. Comparison of the results of the 1995 and 2003/4 surveys revealed improved recognition of depression and schizophrenia as well as more positive ratings for a range of interventions, including help from mental health professionals, medications, psychotherapy and psychiatric ward admission. ${ }^{9}$ In the context of further efforts to improve mental health literacy in the Australian population, the aim of the current survey was to investigate whether recognition of mental disorders and beliefs about treatments and outcomes have changed over a 16-year period.

\section{Method}

\section{The 1995 survey}

The 1995 survey was carried out by the Australian Bureau of Statistics and the method has been described by Jorm and colleagues. ${ }^{1}$ Contact was made with 2531 households in both urban and rural areas. One person aged $18-75$ years was randomly sampled per household and 2164 people (85\%) agreed to participate.

The interview was based on a vignette of a person with depression or schizophrenia (chosen to present one high prevalence and one low prevalence disorder). Participants were randomly assigned to receive either vignette and were also assigned to receive either a male ('John') or a female ('Mary') version of the vignette. Respondents were then asked what, if anything, they thought was wrong with the person, and how they thought the person could best be helped. They were then asked to rate the likely helpfulness of a range of interventions (rated as likely to be helpful, harmful or neither) for the person in the vignette. The interventions were: a typical general practitioner (GP) or family doctor; a typical chemist (pharmacist); a counsellor; a social worker; a telephone counselling service, such as Lifeline; a psychiatrist; a psychologist; help from close family; help from close friends; a naturopath or a herbalist; the clergy, a minister or priest; John/Mary tried to deal with his/her problems on his/her own; vitamins and minerals, tonics or herbal medicines; pain relievers, such as aspirin, codeine or paracetamol; antidepressants; antibiotics; sleeping pills; antipsychotics; tranquillisers, such as valium; becoming physically more active, such as playing more sport, or doing a lot more walking or gardening; reading about people with similar problems and how they have dealt with them; getting out and about more; attending courses on relaxation, stress management, meditation or yoga; cutting out alcohol altogether; psychotherapy; hypnosis; being 
admitted to a psychiatric ward of a hospital; undergoing electroconvulsive therapy (ECT); having an occasional alcoholic drink to relax; and going on a special diet or avoiding certain foods.

Respondents were also asked questions about the likely outcome for the person in the vignette with and without appropriate professional help. The response options were: full recovery with no further problems; full recovery, but problems would probably re-occur; partial recovery; partial recovery, but problems would probably re-occur; no improvement; and get worse.

The rest of the interview involved questions on knowledge of causes and risk factors, beliefs associated with stigma and discrimination, contact with people such as those in the vignette and the health of the respondent. These analyses are not reported here.

\section{The 2003/4 survey}

The method used in the 2003/4 survey, which was carried out by the company AC Nielsen and aimed to replicate the methodology of the earlier survey as closely as possible, has been previously described. ${ }^{8}$ Households were sampled from 250 census districts covering all states and territories and metropolitan and rural areas. To achieve a target sample of 4000 interviews with adults aged 18 years or over, visits were made to 28947 households. The achieved sample was 3998 respondents and the response rate $34 \%$.

In addition to the depression and schizophrenia vignettes used in the 1995 survey, the 2003/4 survey included two additional vignettes: depression with suicidal thoughts and chronic schizophrenia. It also incorporated all the questions of the earlier survey and some additional questions that are not used in the present analyses.

\section{The 2011 survey}

The method used in the 2011 survey, which involved computerassisted telephone interviews with 6019 respondents aged 15+, is reported elsewhere. ${ }^{10}$ The survey was carried out by the company The Social Research Centre, with the sample contacted by random-digit dialling of both landlines and mobile telephones covering the whole country from January to May 2011. The response rate was $44.0 \%$, defined as completed interviews $(n=6019)$ out of sample members who could be contacted and were confirmed as 'in scope' $(n=13636)$. The survey interview was based on those used in the 1995 and 2003/4 surveys and also included two additional vignettes: social phobia and posttraumatic stress disorder. As these vignettes are not used in the present analyses, they are not described here.

\section{Statistical analyses}

The data were initially analysed using percentage frequencies and $95 \%$ confidence intervals. In order to yield better population estimates, the analyses used sample weights that took account of the number of people in the household, telephone type (mobile or landline), age, gender and geographic location. Because of the large sample sizes, even very small differences between surveys can be statistically significant. We therefore focused on the effect sizes of the differences between surveys. The interpretation is focused on those effect sizes that equal or exceed Cohen's definition of a 'small' $(h \geqslant 0.2)$ effect size. ${ }^{11}$

As the 1995 survey only included the depression and chronic schizophrenia vignettes, comparison over three time points was only possible for responses relating to these vignettes. The 2003/4 survey also included the depression with suicidal thoughts and chronic schizophrenia vignettes, thus for data relating to these vignettes, comparison over two time points was possible.

The 1995 and 2003/4 surveys only included adults aged 18+, and to make the samples comparable, those aged 15-17 from the 2011 survey were dropped from the analyses reported here. For comparisons between the 2003/4 and 2011 surveys, this left a total of 3915 respondents: 992 people who received the depression vignette, 979 who received the depression with suicidal thoughts vignette, 972 who received the early schizophrenia vignette and 972 who received the chronic schizophrenia vignette. For comparisons that included the 1995 survey results, those aged $75+$ from the 2011 survey were also dropped from the analyses reported here. This left a total of 3603 respondents: 893 people who received the depression vignette, 903 who received the depression with suicidal thoughts vignette, 892 who received the early schizophrenia vignette and 915 who received the chronic schizophrenia vignette. All analyses were performed using Intercooled Stata 10 for Windows.

\section{Results}

\section{Recognition of disorders}

Table 1 shows the percentage of respondents mentioning each category to describe the problem shown in the vignette, along with the changes between the three surveys that involved a small effect size or greater. The proportion of respondents who correctly identified depression increased between 1995 and 2011, and the numbers of people labelling depression as a 'nervous breakdown', a 'psychological/mental/emotional problem' or 'stress' decreased. Similar changes for the vignette about depression with suicidal thoughts were seen between 2003/4 and 2011 .

For the early schizophrenia vignette, the percentage of respondents identifying this as 'psychosis' or 'schizophrenia'

\begin{tabular}{|c|c|c|c|c|c|c|c|c|c|c|c|c|}
\hline \multirow[b]{2}{*}{ Category mentioned } & \multicolumn{3}{|c|}{ Depression } & \multicolumn{3}{|c|}{ Depression with suicidal thoughts } & \multicolumn{3}{|c|}{ Early schizophrenia } & \multicolumn{3}{|c|}{ Chronic schizophrenia } \\
\hline & 1995 & $2003 / 4$ & 2011 & 1995 & $2003 / 4$ & 2011 & 1995 & $2003 / 4$ & 2011 & 1995 & $2003 / 4$ & 2011 \\
\hline Depression & 39.0 & $67.3^{\mathrm{a}}$ & $73.9^{\mathrm{b}}$ & - & 77.3 & $86.1^{c}$ & 26.3 & $36.2^{\mathrm{a}}$ & $38.1^{\mathrm{a}}$ & - & 9.6 & 5.7 \\
\hline Schizophrenia/psychosis & 0.1 & 0 & 0 & - & 0.5 & 0.5 & 26.8 & $42.5^{\mathrm{a}}$ & $37.9^{\mathrm{a}}$ & - & 36.1 & 32.1 \\
\hline Nervous breakdown & 2.2 & 0.7 & $0.2^{\mathrm{b}}$ & - & 1.6 & 0 & 3.2 & 1.4 & $0^{a, b}$ & - & 1.0 & 0.1 \\
\hline $\begin{array}{l}\text { Psychological/emotional } \\
\text { and mental problems }\end{array}$ & 8.6 & 4.4 & $1.7^{\mathrm{b}}$ & - & 6.0 & $2.7^{c}$ & 15.2 & 12.5 & $8.3^{b}$ & - & 14.3 & 10.1 \\
\hline Mental illness & 1.5 & 2.8 & 2.9 & - & 5.5 & 4.0 & 15.6 & $23.7^{\mathrm{a}}$ & 18.7 & - & 35.8 & 35.7 \\
\hline Stress & 22.1 & 17.6 & $7.0^{\mathrm{b}, \mathrm{c}}$ & - & 10.9 & $2.7^{c}$ & 5.9 & 2.9 & $1.3^{b}$ & - & 2.8 & $0.1^{\mathrm{c}}$ \\
\hline
\end{tabular}




\begin{tabular}{|c|c|c|c|c|c|c|c|c|c|c|c|c|}
\hline \multirow[b]{2}{*}{ Category } & \multicolumn{3}{|c|}{ Depression } & \multicolumn{3}{|c|}{ Depression with suicidal thoughts } & \multicolumn{3}{|c|}{ Early schizophrenia } & \multicolumn{3}{|c|}{ Chronic schizophrenia } \\
\hline & 1995 & $2003 / 4$ & 2011 & 1995 & $2003 / 4$ & 2011 & 1995 & $2003 / 4$ & 2011 & 1995 & $2003 / 4$ & 2011 \\
\hline Family/friends & 19.9 & 23.4 & $9.4^{\mathrm{b}, \mathrm{c}}$ & - & 24.0 & $12.5^{\mathrm{c}}$ & 20.1 & 24.0 & $9.7^{b, c}$ & - & 14.4 & $5.7^{\mathrm{C}}$ \\
\hline $\begin{array}{l}\text { Doctor/general } \\
\text { practitioner }\end{array}$ & 35.2 & $56.9^{\mathrm{a}}$ & $44.8^{b, c}$ & - & 49.3 & $33.7^{\mathrm{C}}$ & 26.5 & 49.3 & $24.8^{c}$ & - & 21.0 & $13.2^{\mathrm{c}}$ \\
\hline Psychiatrist & 18.5 & 11.8 & $3.1^{b, c}$ & - & 18.2 & $5.3^{c}$ & 28.3 & 18.2 & $14.9^{\mathrm{b}, \mathrm{c}}$ & - & 27.9 & $13.8^{c}$ \\
\hline Medication & 2.8 & 6.5 & $1.9^{\mathrm{c}}$ & - & 8.7 & $2.3^{c}$ & 3.5 & 8.7 & $3.8^{\mathrm{C}}$ & - & 11.7 & $5.7^{\circ}$ \\
\hline Counsellor/counselling & 27.0 & 28.9 & $14.8^{\mathrm{b}, \mathrm{c}}$ & - & 37.4 & $17.8^{\mathrm{C}}$ & 31.0 & 37.4 & $12.6^{\mathrm{b}, \mathrm{c}}$ & - & 20.8 & $9.4^{\mathrm{C}}$ \\
\hline $\begin{array}{l}\text { Person must first } \\
\text { recognise problem }\end{array}$ & 5.2 & 4.8 & $0.8^{\mathrm{b}, \mathrm{c}}$ & - & 6.6 & $1.1^{\mathrm{c}}$ & 6.0 & 6.6 & $1.5^{\mathrm{b}}$ & - & 6.0 & $1.4^{\mathrm{C}}$ \\
\hline Don't know & 4.7 & 1.5 & 3.0 & - & 2.5 & 1.8 & 4.3 & 2.5 & 2.4 & - & 4.8 & 5.5 \\
\hline Other & - & - & - & - & 36.0 & 20.1 & - & - & - & - & 49.8 & $39.0^{\circ}$ \\
\hline
\end{tabular}

increased between 1995 and 2003/4 and between 1995 and 2011. However, use of the label 'depression' for this vignette also increased between 1995 and 2003/4 and between 1995 and 2011.

\section{Best method of help}

Table 2 shows the changes in responses to the open-ended question about how the person in the vignette could best be helped. For depression, between 1995 and 2011 and 2003/4 and 2011 there were decreases in the nomination of family/friends, psychiatrists and counsellors as the best type of help. There was also a decrease in the nomination of medication between 2003/4 and 2011. On the other hand, there was an increase in the nomination of a GP as the best person to help between 1995 and 2011.

For the depression with suicidal thoughts vignette, there were decreases in the nomination of family/friends, GPs, psychiatrists, medication and counsellors as the best type of help between 2003/4 and 2011. Similar results were seen for the early and chronic schizophrenia vignettes.

\section{Beliefs about specific interventions}

Table 3 shows changes in the percentage of the population giving ratings of likely helpfulness for various interventions, and Table 4 shows the percentage giving ratings of likely harmfulness.

\section{People who could help}

For depression, the biggest changes between 1995 and 2011 were for beliefs in the likely helpfulness of GPs, pharmacists, counsellors, social workers, telephone counselling, psychiatrists, psychologists and close friends. The greatest changes in beliefs about likely helpfulness between 2003/4 and 2011 were for telephone counselling and psychiatrists. Beliefs about the likely helpfulness of dealing with the problem alone declined between 1995 and 2011. For depression with suicidal thoughts, beliefs about the likely helpfulness of telephone counselling, psychiatrists and psychologists increased between 2003/4 and 2011.

For early schizophrenia, the biggest changes between 1995 and 2011 were for beliefs in the likely helpfulness of GPs, pharmacists, social workers, telephone counselling, psychiatrists, psychologists, close friends and naturopaths. Belief in the likely helpfulness of GPs, telephone counselling and psychologists increased between 2003/4 and 2011. Beliefs about the likely helpfulness of dealing with the problem alone declined between 1995 and 2011. For chronic schizophrenia, changes were very small.
For depression, belief in the likely harmfulness of psychologists decreased between 1995 and 2003/4 and belief in the likely harmfulness of dealing with the problem alone increased. For depression with suicidal thoughts, belief in the likely harmfulness of social workers, psychiatrists and psychologists decreased between 2003/4 and 2011. For early schizophrenia, belief in the likely harmfulness of psychologists and psychiatrists decreased and belief in the likely harmfulness of dealing with the problem alone increased. For chronic schizophrenia, changes were again very small.

\section{Medications}

For depression, the biggest changes between 1995 and 2011 were for beliefs in the likely helpfulness of antidepressants, antipsychotics and tranquillisers. For both depression vignettes, the greatest increase in beliefs about likely helpfulness between 2003/4 and 2011 was for antidepressants.

For early schizophrenia, the biggest changes between 1995 and 2011 were for beliefs in the likely helpfulness of antidepressants, antipsychotics and tranquillisers. The greatest increase in beliefs about likely helpfulness between 2003/4 and 2011 was for antipsychotics. For chronic schizophrenia, the greatest increases in beliefs about likely helpfulness between 2003/4 and 2011 were for antidepressants and antipsychotics.

For depression, belief in the likely harmfulness of antidepressants, antipsychotics and tranquillisers decreased between 1995 and 2003/4, and belief in the likely harmfulness of antipsychotics also decreased between 2003/4 and 2011. For depression with suicidal thoughts, all changes were very small. For early schizophrenia, belief in the likely harmfulness of antidepressants and antipsychotics decreased. For chronic schizophrenia, belief in the likely harmfulness of antidepressants, antibiotics, antipsychotics and tranquillisers decreased between 2003/4 and 2011.

\section{Other interventions}

For depression, the biggest increases between 1995 and 2011 were for beliefs in the likely helpfulness of physical activity, reading about the problem, getting out more, relaxation, cutting out alcohol, psychotherapy, hypnosis, admission to a psychiatric ward and going on a special diet. The greatest changes in beliefs about likely helpfulness between 2003/4 and 2011 were for getting out more, cutting out alcohol and hypnosis. For depression with suicidal thoughts, belief in the likely helpfulness of cutting out 
Table 3 Percentage of respondents rating each intervention as 'helpful' for the person described in the vignette

\begin{tabular}{|c|c|c|c|c|c|c|c|c|c|c|c|c|}
\hline \multirow[b]{2}{*}{ Intervention } & \multicolumn{3}{|c|}{ Depression } & \multicolumn{3}{|c|}{ Depression with suicidal thoughts } & \multicolumn{3}{|c|}{ Early schizophrenia } & \multicolumn{3}{|c|}{ Chronic schizophrenia } \\
\hline & 1995 & $2003 / 4$ & 2011 & 1995 & $2003 / 4$ & 2011 & 1995 & $2003 / 4$ & 2011 & 1995 & $2003 / 4$ & 2011 \\
\hline \multicolumn{13}{|l|}{ Person } \\
\hline General practitioner & 82.6 & 87.0 & $90.2^{\mathrm{b}}$ & - & 84.1 & 87.8 & 74.1 & 76.4 & $88.8^{b, c}$ & - & 76.3 & 82.9 \\
\hline Pharmacist & 26.2 & 34.5 & $41.5^{\mathrm{b}}$ & - & 33.2 & 38.1 & 16.1 & 23.0 & $26.5^{\mathrm{b}}$ & - & 28.1 & 35.0 \\
\hline Counsellor & 74.1 & 82.9 & $86.4^{\mathrm{b}}$ & - & 85.5 & 86.3 & 81.3 & 86.4 & 86.8 & - & 83.1 & 86.7 \\
\hline Social worker & 47.8 & $63.0^{\mathrm{a}}$ & $64.1^{\mathrm{b}}$ & - & 67.2 & 71.4 & 57.9 & $69.3^{\mathrm{a}}$ & $72.6^{\mathrm{b}}$ & - & 79.1 & 83.0 \\
\hline Telephone counselling & 53.3 & $64.4^{\mathrm{a}}$ & $75.2^{\mathrm{b}, \mathrm{c}}$ & - & 66.2 & $79.9^{\mathrm{C}}$ & 52.9 & 58.2 & $74.9^{b, c}$ & - & 47.5 & 54.7 \\
\hline Psychiatrist & 50.6 & $65.5^{\mathrm{a}}$ & $74.5^{b, c}$ & - & 71.3 & $84.1^{\mathrm{c}}$ & 70.7 & $81.7^{\mathrm{a}}$ & $88.0^{\mathrm{b}}$ & - & 80.2 & 84.9 \\
\hline Psychologist & 48.7 & $68.2^{\mathrm{a}}$ & $75.5^{\mathrm{b}}$ & - & 69.7 & $82.5^{c}$ & 61.6 & $75.4^{\mathrm{a}}$ & $85.0^{b, c}$ & - & 74.9 & 80.3 \\
\hline Close family & 70.1 & 68.4 & 70.9 & - & 64.8 & 71.8 & 60.8 & 63.0 & 65.8 & - & 61.4 & 67.3 \\
\hline Close friends & 72.5 & 78.8 & $81.6^{\mathrm{b}}$ & - & 77.1 & 79.8 & 64.5 & 73.2 & $74.2^{\mathrm{b}}$ & - & 72.0 & 79.5 \\
\hline Naturopath & 29.8 & 35.8 & 34.0 & - & 31.8 & 32.5 & 15.7 & $24.4^{\mathrm{a}}$ & $23.6^{\mathrm{b}}$ & - & 19.4 & 22.9 \\
\hline Clergy & 43.8 & 45.0 & 46.5 & - & 51.7 & 50.5 & 41.0 & 36.8 & 40.3 & - & 42.9 & 44.7 \\
\hline Deal with alone & 28.6 & $12.4^{\mathrm{a}}$ & $9.8^{\mathrm{b}}$ & - & 9.7 & 7.3 & 22.3 & $10.8^{\mathrm{a}}$ & $8.5^{\mathrm{b}}$ & - & 11.8 & 8.9 \\
\hline \multicolumn{13}{|l|}{ Medication } \\
\hline Vitamins/minerals & 56.8 & 50.4 & 49.2 & - & 43.7 & 46.1 & 34.3 & 31.7 & 36.8 & - & 33.2 & 37.5 \\
\hline Pain relievers & 10.6 & 13.9 & 15.3 & - & 12.3 & 11.2 & 8.5 & 6.7 & 9.0 & _- & 10.2 & 11.1 \\
\hline Antidepressants & 28.7 & $47.8^{\mathrm{a}}$ & $59.0^{b, c}$ & - & 52.5 & $63.6^{\mathrm{C}}$ & 38.5 & $50.5^{\mathrm{a}}$ & $60.0^{\mathrm{b}}$ & - & 42.6 & $56.2^{c}$ \\
\hline Antibiotics & 8.7 & 10.1 & 10.2 & - & 7.9 & 7.0 & 4.8 & 3.6 & 6.0 & - & 6.4 & 10.6 \\
\hline Sleeping pills & 15.9 & 23.5 & 22.0 & - & 21.9 & 21.3 & 13.0 & 17.9 & 19.2 & - & 11.6 & 16.0 \\
\hline Antipsychotics & 6.1 & $12.0^{\mathrm{a}}$ & $18.3^{\mathrm{b}}$ & - & 16.5 & 20.8 & 23.2 & $34.4^{\mathrm{a}}$ & $48.3^{b, c}$ & - & 38.2 & $52.3^{\mathrm{c}}$ \\
\hline Tranquillisers & 7.6 & 13.6 & $17.3^{\mathrm{b}}$ & - & 13.8 & 16.5 & 13.0 & 16.8 & $22.9^{\mathrm{b}}$ & - & 15.3 & 21.4 \\
\hline \multicolumn{13}{|l|}{ Other interventions } \\
\hline Physical activity & 81.2 & $92.0^{\mathrm{a}}$ & $95.7^{\mathrm{b}}$ & - & 92.5 & 95.9 & 83.0 & 87.4 & $92.8^{\mathrm{b}}$ & - & 79.6 & 86.3 \\
\hline Read about problem & 67.5 & $80.1^{\mathrm{a}}$ & $86.0^{\mathrm{b}}$ & - & 79.8 & 86.2 & 74.7 & 80.8 & $85.6^{\mathrm{b}}$ & - & 74.7 & 80.4 \\
\hline Get out more & 82.0 & 86.5 & $93.0^{b, c}$ & - & 90.3 & 93.3 & 83.3 & 87.1 & $90.1^{b}$ & - & 76.5 & 80.6 \\
\hline Learn relaxation & 80.0 & 84.3 & $87.7^{b}$ & - & 85.3 & 90.3 & 73.4 & 77.4 & $85.0^{b, c}$ & _- & 68.7 & 75.9 \\
\hline Cut out alcohol & 56.7 & 55.8 & $74.0^{b, c}$ & - & 59.8 & $76.6^{\mathrm{c}}$ & 64.2 & 66.4 & $81.7^{b, c}$ & - & 53.4 & $75.5^{\mathrm{c}}$ \\
\hline Psychotherapy & 33.7 & $44.4^{\mathrm{a}}$ & $44.9^{\mathrm{b}}$ & - & 50.4 & 50.4 & 54.7 & 60.1 & 60.9 & _- & 62.3 & 63.8 \\
\hline Hypnosis & 18.7 & 22.4 & $33.5^{b, c}$ & - & 23.9 & $34.2^{\mathrm{c}}$ & 21.0 & $30.5^{a}$ & $36.4^{b}$ & - & 30.9 & 33.1 \\
\hline Psychiatric ward & 6.7 & $16.7^{\mathrm{a}}$ & $22.8^{\mathrm{b}}$ & - & 20.2 & $33.1^{\mathrm{c}}$ & 18.2 & $32.8^{\mathrm{a}}$ & $43.2^{b, c}$ & - & 37.8 & $52.2^{\mathrm{c}}$ \\
\hline $\begin{array}{l}\text { Electroconvulsive } \\
\text { therapy }\end{array}$ & 3.0 & 5.9 & 6.5 & - & 7.2 & 8.8 & 4.5 & 6.2 & 9.3 & - & 6.5 & 8.9 \\
\hline Occasional drink & 36.6 & 43.0 & 39.5 & - & 41.8 & 36.4 & 22.4 & 30.4 & 24.9 & - & $\begin{array}{r}0.5 \\
27.3\end{array}$ & $\begin{array}{r}0.9 \\
22.6\end{array}$ \\
\hline Special diet & 40.5 & 487 & $577^{\mathrm{b}}$ & _- & 45.6 & 52.3 & 30.8 & $422^{\mathrm{a}}$ & $53,1^{b, c}$ & _- & 39.3 & $54.9^{\circ}$ \\
\hline Website & - & 57.9 & 60.9 & - & 55.1 & 62.7 & - & 57.5 & 63.7 & - & 44.1 & 53.5 \\
\hline Expert via email & - & 53.8 & 59.8 & - & 49.6 & $64.2^{\mathrm{C}}$ & - & 55.4 & 62.6 & - & 44.7 & $54.8^{\mathrm{c}}-x-1$ \\
\hline Book & _- & 69.1 & 69.2 & - & 64.7 & 70.2 & _- & 70.5 & 70.5 & _- & 59.2 & 64.6 \\
\hline Health educator & - & 86.7 & 90.2 & - & 85.9 & 90.0 & - & 86.2 & $92.3^{c}$ & - & 83.8 & $91.6^{\mathrm{C}}-\mathrm{x}$ \\
\hline
\end{tabular}

alcohol, hypnosis, admission to a psychiatric ward and contact with an expert via email increased between 2003/4 and 2011.

For early schizophrenia, the biggest changes between 1995 and 2011 were for beliefs in the likely helpfulness of physical activity, reading about the problem, getting out more, relaxation, cutting out alcohol, hypnosis, admission to a psychiatric ward and going on a special diet. The greatest changes in beliefs about likely helpfulness between 2003/4 and 2011 were for relaxation, cutting out alcohol, admission to a psychiatric ward and going on a special diet. For chronic schizophrenia, belief in the likely helpfulness of cutting out alcohol, admission to a psychiatric ward, going on a special diet, contact with an expert via email and seeing a health educator changed between 2003/4 and 2011.

For depression, belief in the likely harmfulness of admission to a psychiatric ward and ECT decreased between 1995 and 2003/4, and belief in the likely harmfulness of an occasional drink of alcohol increased. Belief in the likely harmfulness of admission to a psychiatric ward also decreased between 2003/4 and 2011, and belief in the likely harmfulness of an occasional drink of alcohol increased. For depression with suicidal thoughts, belief in the likely harmfulness of psychotherapy, hypnosis, admission to a psychiatric ward and ECT decreased between 1995 and
$2003 / 4$, and belief in the likely harmfulness of an occasional drink of alcohol increased.

For early schizophrenia, belief in the likely harmfulness of admission to a psychiatric ward decreased between 1995 and 2003/4, and belief in the likely harmfulness of an occasional drink of alcohol increased. Belief in the likely harmfulness of ECT decreased between 2003/4 and 2011, and belief in the likely harmfulness of an occasional drink of alcohol increased. For chronic schizophrenia, belief in the likely harmfulness of admission to a psychiatric ward and ECT decreased between 1995 and 2003/4, and belief in the likely harmfulness of an occasional drink of alcohol increased.

\section{Beliefs about likely outcomes for those with mental disorders}

Table 5 shows changes in respondents' views about the likely outcomes if the person described in the vignette either had appropriate professional help or did not. For those who received professional help for depression, belief in full recovery with no further problems decreased between 1995 and 2011 and between 2003/4 and 2011. Belief in full recovery with later relapse increased between 1995 and 2011, as did belief in partial recovery with later 
Table 4 Percentage of respondents rating each intervention as 'harmful' for the person described in the vignette

\begin{tabular}{|c|c|c|c|c|c|c|c|c|c|c|c|c|}
\hline \multirow[b]{2}{*}{ Intervention } & \multicolumn{3}{|c|}{ Depression } & \multicolumn{3}{|c|}{ Depression with suicidal thoughts } & \multicolumn{3}{|c|}{ Early schizophrenia } & \multicolumn{3}{|c|}{ Chronic schizophrenia } \\
\hline & 1995 & $2003 / 4$ & 2011 & 1995 & $2003 / 4$ & 2011 & 1995 & $2003 / 4$ & 2011 & 1995 & $2003 / 4$ & 2011 \\
\hline \multicolumn{13}{|l|}{ Person } \\
\hline General practitioner & 1.6 & 0.6 & 0.6 & - & 1.1 & 1.5 & 1.8 & 2.5 & 1.6 & - & 2.7 & 1.9 \\
\hline Pharmacist & 8.3 & 9.1 & 6.4 & - & 8.1 & 7.4 & 8.4 & 8.8 & 10.6 & - & 8.2 & 6.9 \\
\hline Counsellor & 1.5 & 3.2 & 1.6 & - & 2.3 & 1.8 & 2.0 & 3.1 & 1.3 & - & 2.4 & 1.7 \\
\hline Social worker & 5.5 & 4.7 & 3.2 & - & 5.5 & $1.9^{3}$ & 6.2 & 4.1 & 4.0 & - & 3.0 & 3.3 \\
\hline Telephone counselling & 5.6 & 6.0 & 2.9 & - & 6.3 & 2.6 & 6.4 & 7.7 & 3.8 & - & 11.1 & 7.9 \\
\hline Psychiatrist & 8.9 & 7.1 & 5.8 & - & 8.1 & $2.1^{3}$ & 6.4 & 5.2 & $1.8^{\mathrm{b}}$ & - & 4.6 & 3.7 \\
\hline Psychologist & 7.8 & 5.1 & $3.0^{\mathrm{b}}$ & - & 5.2 & $1.1^{3}$ & 5.2 & 3.1 & $1.5^{\mathrm{b}}$ & - & 3.6 & 1.8 \\
\hline Close family & 3.6 & 4.8 & 3.9 & - & 4.1 & 3.7 & 6.8 & 5.6 & 5.0 & - & 5.3 & 4.1 \\
\hline Close friends & 4.4 & 2.1 & 2.5 & - & 2.6 & 2.7 & 5.2 & 3.2 & 3.9 & - & 3.3 & 2.4 \\
\hline Naturopath & 9.8 & 10.9 & 11.1 & - & 13.3 & 11.8 & 15.5 & 15.5 & 16.1 & - & 15.0 & 13.3 \\
\hline Clergy & 6.4 & 7.7 & 8.2 & - & 9.3 & 7.7 & 8.1 & 12.0 & 11.9 & - & 10.3 & 9.4 \\
\hline Deal with alone & 43.0 & $64.5^{\mathrm{a}}$ & $68.4^{\mathrm{b}}$ & - & 74.8 & 77.7 & 55.3 & $70.6^{\mathrm{a}}$ & $77.5^{\mathrm{b}}$ & - & 67.7 & 72.5 \\
\hline \multicolumn{13}{|l|}{ Medication } \\
\hline Vitamins/minerals & 3.3 & 4.3 & 5.3 & - & 5.4 & 6.4 & 5.3 & 5.9 & 7.3 & - & 6.4 & 6.4 \\
\hline Pain relievers & 41.4 & 38.5 & 40.8 & - & 37.3 & 42.1 & 36.0 & 40.0 & 41.2 & _- & 34.5 & 36.3 \\
\hline Antidepressants & 41.8 & $27.2^{\mathrm{a}}$ & $20.1^{\mathrm{b}}$ & - & 23.4 & 16.1 & 32.4 & $23.1^{\mathrm{a}}$ & $17.2^{\mathrm{b}}$ & - & 29.3 & $17.9^{c}$ \\
\hline Antibiotics & 32.7 & 38.9 & 35.0 & - & 37.8 & 34.4 & 31.6 & 36.9 & 32.1 & - & 36.9 & $27.3^{\mathrm{c}}$ \\
\hline Sleeping pills & 53.7 & 50.3 & 51.8 & - & 50.3 & 54.1 & 52.9 & 54.3 & 52.1 & - & 58.8 & 50.0 \\
\hline Antipsychotics & 51.0 & 48.8 & $34.3^{\mathrm{b}, \mathrm{c}}$ & - & 40.4 & 32.8 & 33.7 & 24.1 & $18.9^{\mathrm{b}}$ & - & 24.5 & $14.7^{c}$ \\
\hline Tranquillisers & 65.5 & 61.2 & $54.8^{b}$ & - & 60.1 & 52.8 & 53.5 & 48.9 & 44.8 & - & 55.7 & $41.8^{\mathrm{C}}$ \\
\hline \multicolumn{13}{|l|}{ Other intervention } \\
\hline Physical activity & 2.2 & 0.8 & 0.5 & - & 0.3 & 0.7 & 1.0 & 0.4 & 1.1 & - & 0.6 & 1.0 \\
\hline Read about problem & 7.4 & 3.7 & 4.8 & - & 5.2 & 2.7 & 3.7 & 4.1 & 3.9 & - & 3.6 & 3.7 \\
\hline Get out more & 1.0 & 0.4 & 0.3 & - & 0.3 & 0.1 & 1.5 & 1.7 & 1.4 & - & 2.2 & 2.4 \\
\hline Learn relaxation & 1.6 & 1.2 & 1.7 & - & 0.8 & 0.6 & 1.8 & 0.9 & 1.2 & - & 3.6 & 1.5 \\
\hline Cut out alcohol & 3.6 & 4.6 & 3.9 & - & 5.3 & 5.0 & 2.5 & 3.0 & 4.1 & - & 2.7 & 1.9 \\
\hline Psychotherapy & 12.5 & 9.7 & 7.4 & - & 10.6 & $4.8^{\mathrm{c}}$ & 7.3 & 5.6 & 4.9 & _- & 7.2 & 4.8 \\
\hline Hypnosis & 20.2 & 16.3 & 14.0 & - & 20.4 & $10.8^{c}$ & 17.1 & 12.5 & 11.2 & - & 16.7 & 12.2 \\
\hline Psychiatric ward & 61.7 & 53.4 & $41.8^{b, c}$ & - & 49.2 & $32.4^{c}$ & 51.3 & $38.3^{\mathrm{a}}$ & $28.2^{\mathrm{b}}$ & - & 33.2 & $20.7^{c}$ \\
\hline $\begin{array}{l}\text { Electroconvulsive } \\
\text { therapy }\end{array}$ & 72.2 & 69.4 & $61.5^{\mathrm{b}}$ & - & 65.9 & $56.3^{c}$ & 65.5 & 63.2 & $56.6^{c}$ & - & 65.4 & $54.5^{c}$ \\
\hline Occasional drink & 17.6 & 15.1 & $26.9^{b, c}$ & - & 19.1 & $32.0^{c}$ & 30.2 & 30.1 & $42.4^{b, c}$ & - & 25.2 & $45.2^{\mathrm{c}}$ \\
\hline Special diet & 8.5 & 7.8 & 5.7 & - & 9.2 & 7.8 & 7.7 & 7.8 & 8.8 & - & 7.1 & 6.8 \\
\hline Website & - & 14.8 & 18.5 & - & 15.3 & 18.0 & - & 12.7 & 16.8 & - & 19.3 & 20.9 \\
\hline Expert via email & - & 14.3 & 13.1 & - & 16.4 & 14.2 & - & 13.8 & 15.2 & - & 17.3 & 16.3 \\
\hline Book & - & 7.7 & 11.4 & - & 9.0 & 10.9 & - & 7.1 & 9.8 & - & 9.4 & 11.7 \\
\hline Health educator & - & 1.4 & 2.1 & - & 2.0 & 1.7 & - & 1.4 & 1.1 & - & 1.6 & 1.0 \\
\hline
\end{tabular}

\begin{tabular}{|c|c|c|c|c|c|c|c|c|c|c|c|c|}
\hline \multirow[b]{2}{*}{ Category } & \multicolumn{3}{|c|}{ Depression } & \multicolumn{3}{|c|}{ Depression with suicidal thoughts } & \multicolumn{3}{|c|}{ Early schizophrenia } & \multicolumn{3}{|c|}{ Chronic schizophrenia } \\
\hline & 1995 & $2003 / 4$ & 2011 & 1995 & $2003 / 4$ & 2011 & 1995 & $2003 / 4$ & 2011 & 1995 & $2003 / 4$ & 2011 \\
\hline \multicolumn{13}{|l|}{ With professional help } \\
\hline Full recovery & 42.5 & 37.9 & $23.0^{\mathrm{b}, \mathrm{c}}$ & - & 29.6 & 22.7 & 28.3 & $25.1^{\mathrm{a}}$ & $16.6^{\mathrm{b}, \mathrm{c}}$ & - & 15.8 & $8.1^{\mathrm{c}}$ \\
\hline Full recovery with relapse & 37.3 & 44.1 & $47.4^{\mathrm{b}}$ & - & 48.2 & 47.0 & 40.9 & 48.4 & 45.7 & - & 38.9 & $28.9^{\mathrm{C}}$ \\
\hline Partial recovery & 6.7 & 9.5 & 9.2 & - & 9.0 & 10.5 & 11.2 & 12.1 & 13.4 & - & 19.1 & 19.0 \\
\hline Partial recovery with relapse & 6.5 & 5.3 & $13.2^{\mathrm{b}, \mathrm{c}}$ & _- & 9.5 & 14.3 & 13.9 & $11.9^{\mathrm{a}}$ & $19.2^{\mathrm{b}, \mathrm{c}}$ & _- & 21.4 & $38.3^{\mathrm{c}}$ \\
\hline No improvement & 0.2 & 0.1 & 0.4 & - & 0.3 & 0.1 & 0.6 & 0.3 & 0.1 & - & 0.8 & 0.7 \\
\hline Get worse & 0.5 & 0.6 & 0.1 & - & 0.2 & 0.0 & 0.4 & $0.2^{\mathrm{a}}$ & $4.6^{b, c}$ & - & 0.3 & 0.1 \\
\hline Don't know & 6.3 & 2.5 & 6.7 & - & 3.1 & 5.3 & 4.6 & 2.0 & $0.3^{\mathrm{b}}$ & - & 3.6 & 4.8 \\
\hline \multicolumn{13}{|l|}{ Without professional help } \\
\hline Full recovery & 0.9 & 0.7 & 0.7 & - & 0.4 & 0.5 & 0.6 & 0.5 & 0.3 & - & 0.1 & 0.2 \\
\hline Full recovery with relapse & 4.1 & 2.3 & 1.5 & - & 1.5 & 0.9 & 1.9 & 0.7 & 0.5 & - & 0.5 & 0.4 \\
\hline Partial recovery & 4.3 & 2.6 & 3.0 & - & 2.5 & 2.9 & 1.3 & 0.8 & 1.0 & - & 1.2 & 0.7 \\
\hline Partial recovery with relapse & 12.3 & 10.2 & 7.6 & _- & 6.7 & 7.8 & 4.5 & 3.8 & 3.9 & _- & 1.2 & 1.7 \\
\hline No improvement & 16.0 & 18.7 & 13.8 & - & 14.2 & 12.5 & 14.4 & 14.8 & 9.8 & - & 19.4 & 17.2 \\
\hline Get worse & 56.4 & 64.4 & $70.1^{\mathrm{b}}$ & _- & 72.0 & 71.4 & 74.5 & 78.4 & $83.0^{\mathrm{b}}$ & _- & 76.8 & 78.1 \\
\hline Don't know & 6.0 & $1.1^{\mathrm{a}}$ & 3.1 & - & 2.7 & 4.1 & 2.8 & 1.0 & 1.6 & - & 0.9 & 1.5 \\
\hline
\end{tabular}


relapse, which also increased between 2003/4 and 2011. For depression with suicidal thoughts, changes in beliefs about outcomes were very small.

For those who received professional help for early schizophrenia, belief in full recovery with no further problems decreased between 1995 and 2011 and between 2003/4 and 2011. Belief in partial recovery with later relapse increased between 2003/4 and 2011. Belief that the person would get worse increased between 1995 and 2011 and between 2003/4 and 2011, although the percentage with this belief was small. For chronic schizophrenia, belief in full recovery with no further problems decreased between 2003/4 and 2011, as did belief in full recovery with later relapse. Belief in partial recovery with later relapse increased.

For those who did not receive professional help for depression or early schizophrenia, belief that the person would get worse increased between 1995 and 2011. For depression with suicidal thoughts and chronic schizophrenia, changes were very small.

\section{Discussion}

\section{Main findings}

Results of the 2011 national survey revealed that there have been improvements in mental health literacy in the Australian public since the first survey was carried out in 1995. This was particularly notable for improved recognition of depression in a vignette, increase in beliefs about the helpfulness of GPs, psychiatrists and counsellors, and beliefs in the likely helpfulness of medications, particularly antidepressants and antipsychotics. Public beliefs about the likely helpfulness of interventions and outcomes have moved closer to those of health professionals. ${ }^{2}$

It is likely that improved recognition rates for depression partly reflect the efforts of 'beyondblue: the national depression initiative', with results from previous surveys showing changes in mental health literacy to be linked to these campaigns. ${ }^{12}$ Campaigns run by 'beyondblue' have tended to focus on depression and this may also explain the increase in the use of the term depression for the early schizophrenia vignette. Recognition of schizophrenia, particularly early schizophrenia, has also improved over time, although to a lesser degree. These increases were paralleled by a reduction in the use of the lay terms 'nervous breakdown', 'stress' and 'psychological/mental/emotional problems'. Such changes may also arise as a result of a change in common parlance about mental health issues, with 'depression' becoming a more commonly used term across disorders.

Responses to the question about how the person could best be helped showed reductions for all categories other than GPs for depression. However, caution should be used in interpreting these results, as these decreases may be the result of changes in the methodology from face-to-face interviews to telephone interviews. It is possible that respondents nominate a narrower range of options during a telephone interview.

For depression, beliefs in the likely helpfulness of all health professionals, close friends, antidepressants, antipsychotics and tranquillisers increased between 1995 and 2011, with increases for telephone counselling, psychiatrists and antidepressants also occurring between 2003/4 and 2011. The changes in ratings for antidepressants were particularly striking. Approximately twice as many people rated them as likely to be helpful in 2011 compared with 1995, while half as many people rated them as harmful in 2011 compared with 1995. It is possible that these ratings may reflect the increasingly widespread use of antidepressants in the years between the surveys. ${ }^{13}$ Along with 'beyondblue' campaigns, this may also be a factor in the generalisation of beliefs about likely helpfulness of antidepressants for schizophrenia.

Increases in positive ratings for telephone counselling, psychiatrists, psychologists and antidepressants were also seen between 2003/4 and 2011 for depression with suicidal thoughts. Similar changes in ratings were seen for early schizophrenia, with the most notable being in beliefs about the likely helpfulness of antipsychotics. Belief in the harmfulness of antidepressants and antipsychotics also declined between 1995 and 2003/4. Encouragingly, a belief in the likely helpfulness of dealing with depression or schizophrenia by oneself decreased between 1995 and 2003/4, and belief in harmfulness increased. Belief in the likely helpfulness of interventions such as physical activity, getting out more, reading about the problems and cutting out alcohol also increased. It is encouraging to note that there is some evidence for the effectiveness of these interventions in depression. ${ }^{14}$ However, there is no evidence that such interventions are helpful for those with schizophrenia and it is possible that such beliefs may delay access to appropriate treatments. Overall, it appears that although beliefs about effective medications and interventions have moved closer to those of health professionals since earlier surveys, there is still potential for mental health literacy gains in the areas of recognition and treatment beliefs for all the mental disorders covered in this survey, but particularly for schizophrenia.

In general, respondents were more likely to believe in full recovery, with problems re-occurring for those who received appropriate treatment for mental disorders. The exception to this was the chronic schizophrenia vignette for which partial recovery with problems re-occurring was the most common belief. Public beliefs about possible outcomes for those with mental disorders reflected a less optimistic view in 2011 than in 1995, with beliefs about full or partial recovery with relapse for depression and schizophrenia increasing, and belief in full recovery decreasing. In this regard, the public have become more like mental health professionals, who were less optimistic about full recovery when surveyed in the late 1990s. ${ }^{15}$

\section{Findings from other studies}

Although a small number of other studies have examined longitudinal changes in population mental health literacy, one of the unique strengths of the current study is that it enables examination of population changes in mental health literacy over 16 years, a period at least 5 years longer than that of studies with similar methodology. These include South Australian studies comparing depression-related mental health literacy in 1998, 2004 and 2008, ${ }^{16,17}$ and German studies comparing depressionand schizophrenia-related mental health literacy in the 1990s with that in $2001 .^{18,19}$ Similar to the results of the current study, findings from the South Australian study indicated increases in the number of people recognising depression in a vignette and perceiving professional assistance to be more helpful and less harmful. ${ }^{16,17}$ However, there was no significant change in psychiatrists or psychologists being perceived as therapists of choice between 1998 and 2004 and, in fact, providers or treatments were less likely to be rated as 'helpful' in 2008 than in $2004 .^{17}$

In contrast to the South Australian study, studies comparing changes in mental health literacy in West Germany between 1990 and 2001 showed relatively large increases in the willingness to seek help from a psychiatrist or a psychologist, along with more favourable assessment of drug treatment. ${ }^{19}$ In East Germany, some improvements in mental health literacy were seen between 1993 and 2001, particularly in the areas of recognition of disorders and beliefs in the helpfulness of health professionals. ${ }^{18}$ The 
authors of this latter study attributed the improvements to mental health service changes, as there were no public awareness campaigns during the period covered by the surveys.

In other comparable studies, the results of US General Social Surveys showed that public opinions regarding the benefits of psychiatric medications became more favourable between 1998 and 2006, and data from the US National Comorbidity Survey showed that participants in the 2001-2003 survey were more willing than those in the 1990-1992 survey to seek professional help for mental health problems. ${ }^{20,21}$ In the latter survey, participants were also asked a general question about the percentage of people who would be helped if they sought professional help for serious emotional problems. ${ }^{20}$ This changed little between surveys.

\section{Limitations}

Limitations of the study include the relatively low response rates of $34 \%$ and $44 \%$ for the second and third surveys respectively, which may limit the generalisability of the results. A further limitation involves the differences in survey methodology between the surveys. The 1995 and 2003/4 surveys involved household interviews, whereas the 2011 survey adopted computer-assisted telephone interviews as an alternative due to the much greater expense of household surveys. Thus, when comparing the findings from 2011 with the earlier years, some caution was required in interpreting any differences, as the change in method might have affected the results. However, we do have data showing that symptoms of psychological distress have been stable across these three surveys, despite the change in methodology, supporting their comparability. ${ }^{22}$ A further limitation is the lack of data on how beliefs about helpfulness translate into actual help-seeking behaviours, although there is some evidence that intention to seek help is a better predictor of actions than beliefs about helpfulness. ${ }^{23}$ Generalisability of the results to other countries may also be complicated by differences in sociodemographic and health system factors.

\section{Implications}

Beliefs about effective medications and interventions for mental disorders have moved closer to those of health professionals since the surveys conducted in 1995 and 2003/4, but there is still potential for mental health literacy gains in the areas of recognition and treatment beliefs for mental disorders. This is particularly the case for schizophrenia. Although the present survey was carried out in Australia, the goal of improving mental health literacy is seen as important in many countries. The results of the current study suggest that, given sufficient time and investment of resources, quite significant changes in population mental health literacy are possible. The key question is how these changes translate into improvements in population mental health. Further monitoring of population mental health is necessary to explore this. ${ }^{24}$

\footnotetext{
Nicola J. Reavley, PhD, Anthony F. Jorm, PhD, DSC, Orygen Youth Health Research Centre, Centre for Youth Mental Health, University of Melbourne, Parkville, Australia

Correspondence: Nicola J. Reavley, Orygen Youth Health Research Centre, Centre for Youth Mental Health, University of Melbourne, Locked Bag 10, Parkville, VIC 3052, Australia. Email: nreavley@unimelb.edu.au

First received 4 Oct 2011, final revision 8 Dec 2011, accepted 19 Dec 2011
}

\section{References}

1 Jorm AF, Korten AE, Jacomb PA, Christensen $H$, Rodgers B, Pollitt P. 'Mental health literacy': a survey of the public's ability to recognise mental disorders and their beliefs about the effectiveness of treatment. Med J Aust 1997; 166: 182-6.

2 Jorm AF, Korten AE, Jacomb PA, Rodgers B, Pollitt P. Beliefs about the helpfulness of interventions for mental disorders: a comparison of general practitioners, psychiatrists and clinical psychologists. Aust $N$ Z J Psychiatry 1997; 31: 844-51.

3 Caldwell TM, Jorm AF. Mental health nurses' beliefs about interventions for schizophrenia and depression: a comparison with psychiatrists and the public. Aust N Z J Psychiatry 2000; 34: 602-11.

4 Dietrich S, Mergl R, Freudenberg P, Althaus D, Hegerl U. Impact of a campaign on the public's attitudes towards depression. Health Educ Res 2009; 25: 135-50.

5 Evans-Lacko S, London J, Little K, Henderson C, Thornicroft G. Evaluation of a brief anti-stigma campaign in Cambridge: do short-term campaigns work? BMC Public Health 2010; 10: 339

6 Henderson C, Thornicroft G. Stigma and discrimination in mental illness: time to change. Lancet 2009; 373: 1928-30.

7 Dumesnil $\mathrm{H}$, Verger P. Public awareness campaigns about depression and suicide: a review. Psychiatr Serv 2009; 60: 1203-13.

8 Jorm AF, Nakane Y, Christensen H, Yoshioka K, Griffiths KM, Wata Y. Public beliefs about treatment and outcome of mental disorders: a comparison of Australia and Japan. BMC Med 2005; 3: 12.

9 Jorm AF, Christensen $H$, Griffiths KM. The public's ability to recognize mental disorders and their beliefs about treatment: changes in Australia over 8 years. Aust N Z J Psychiatry 2006; 40: 36-41.

10 Reavley NJ, Jorm AF. Recognition of mental disorders and beliefs about treatment and outcome: findings from an Australian National Survey of Mental Health Literacy and Stigma. Aust N Z J Psychiatry 2011; 45: 947-56.

11 Cohen J. A power primer. Psychol Bull 1992; 112: 155-9.

12 Jorm AF, Christensen $H$, Griffiths KM. The impact of beyondblue: the national depression initiative on the Australian public's recognition of depression and beliefs about treatments. Aust N Z J Psychiatry 2005; 39: 248-54.

13 Hollingworth SA, Burgess PM, Whiteford HA. Affective and anxiety disorders: prevalence, treatment and antidepressant medication use. Aust $\mathrm{N} \mathrm{Z} \mathrm{J}$ Psychiatry 2010; 44: 513-9.

14 Morgan AJ, Jorm AF. Self-help interventions for depressive disorders and depressive symptoms: a systematic review. Ann Gen Psychiatry 2008; 7: 13.

15 Caldwell TM, Jorm AF. Mental health nurses' beliefs about likely outcomes for people with schizophrenia or depression: a comparison with the public and other healthcare professionals. Aust N Z J Ment Health Nurs 2001; 10: 42-54.

16 Goldney RD, Fisher LJ, Dal Grande E, Taylor AW. Changes in mental health literacy about depression: South Australia, 1998 to 2004. Med J Aust 2005; 183: $134-7$.

17 Goldney RD, Dunn KI, Dal Grande E, Crabb S, Taylor A. Tracking depressionrelated mental health literacy across South Australia: a decade of change. Aust N Z J Psychiatry 2009; 43: 476-83.

18 Angermeyer MC, Holzinger A, Matschinger $\mathrm{H}$. Mental health literacy and attitude towards people with mental illness: a trend analysis based on population surveys in the eastern part of Germany. Eur Psychiatry 2009; 24: 225-32.

19 Angermeyer MC, Matschinger $\mathrm{H}$. Have there been any changes in the public's attitudes towards psychiatric treatment? Results from representative population surveys in Germany in the years 1990 and 2001. Acta Psychiatr Scand 2005; 111: 68-73.

20 Mojtabai R. Americans' attitudes toward mental health treatment seeking: 1990-2003. Psychiatr Serv 2007; 58: 642-51.

21 Mojtabai R. Americans' attitudes toward psychiatric medications: 1998-2006. Psychiatr Serv 2009; 60: 1015-23.

22 Jorm AF, Reavley NJ. Changes in psychological distress in Australian adults between 1995 and 2011. Aust N Z J Psychiatry 2012; Jan 3 (Epub ahead of print).

23 Reavley N, Yap MBH, Wright A, Jorm AF. Actions taken by young people to deal with mental disorders: findings from an Australian national survey of youth. Early Interv Psychiatry 2011; 5: 335-42.

24 Jorm AF, Barney LJ, Christensen H, Highet NJ, Kelly CM, Kitchener BA. Research on mental health literacy: what we know and what we still need to know. Aust N Z J Psychiatry 2006; 40: 3-5. 